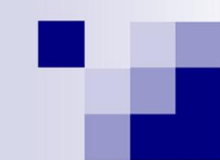

EMERGing SCIEnCE JoURnAL

\section{Emerging Science Journal}

(ISSN: 2610-9182)

Vol. 5, No. 4, August, 2021

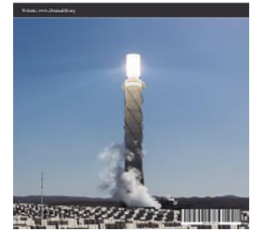

\title{
The Influence of Optimism Bias on Time and Cost on Construction Projects
}

\author{
Aaron Chadee ${ }^{1 *}$, Salisha R. Hernandez ${ }^{1}$, Hector Martin ${ }^{2}$ \\ ${ }^{I}$ Department of Civil and Environmental Engineering, The University of West Indies, St. Augustine, Trinidad and Tobago \\ ${ }^{2}$ School of Civil Engineering and Built Environment, Liverpool John Moores University, Liverpool, UK
}

\begin{abstract}
The unresolved scholarly debate to curtail cost and time performances in projects has led to alternate solutions, departing from the dominant technical school of thought to include concepts from behavioural sciences. In this paper, we consider the psychological effect, namely optimism bias, as one of the root causes for delays in cost overruns on projects. The research objectives were to determine the level of bias among project participants, rank time and cost overrun causes according to the participants' bias score and establish a mitigation strategy to curb potential delays and cost overrun impacts based on the bias scores obtained. A literature survey was conducted to determine causal factors contributing to delays and cost overruns linked to optimism bias. Through a pilot survey of three semi-structured interviews, eighty factors obtained from the literature survey were reduced to 24 critical delay and cost overrun factors relevant to Trinidad and Tobago. A questionnaire was subsequently developed seeking construction professionals to rate their bias scores based on an 11-point Likert scale. The research confirms that project planners and decisionmakers exhibit moderate levels of optimism bias; however, participants lacked awareness of the impact of optimism bias on projects outcomes. Project location, environmental impacts and historic preservation, and labour disputes are the top three critical factors where project professionals displayed increased optimistic tendencies. It is proposed that contingency "time window" and reference class forecasting be implemented as control mechanisms to mitigate the impacts of time and cost overruns on projects. This research introduces a novel method to account for and measure optimism bias on construction projects. This study adds knowledge into delays and cost overruns causation and provides a foundation for future studies on quantifying psychological effects on projects and enhancing overall project management practices.
\end{abstract}

Keywords:

Construction Projects;

Optimism Bias;

Delays;

Cost Overrun;

Consequences;

Mitigation Strategy.

$\begin{array}{lcll}\text { Article History: } & & \\ \text { Received: } & 19 & \text { May } & 2021 \\ \text { Revised: } & 10 & \text { July } & 2021 \\ \text { Accepted: } & 18 & \text { July } & 2021 \\ \text { Published: } & 01 & \text { August } & 2021\end{array}$

\section{1- Introduction}

The inability to accurately forecast construction project costs and time parameters continues to be a worldwide phenomenon and consequently hinders their successful completion. The underlying reasons for these delays and cost overruns vary vastly based on stakeholders' viewpoints such as, but not limited to, geography, economic conditions, technical competency, and governance structures. Similarly, such delays have been noted to be disruptive and expensive [1]. Sinnette [2] uncovered that approximately half of the active projects sampled experienced cost overruns. In the UK, the Taxpayer's Alliance [3] surveyed 305 projects and reported that these projects exceeded initial budgetary allocations by about one-third. Issues based on impractical baseline planning [4], uncertainty and optimism bias [5] have not been accounted for by decision-makers. Inevitably, design errors and omissions, construction mistakes, and contractual conflicts are but a few negative outcomes accepted as a norm in the construction industry [6].

* CONTACT: aaronchadee@hotmail.com

DOI: http://dx.doi.org/10.28991/esj-2021-01287

(C) 2021 by the authors. Licensee ESJ, Italy. This is an open access article under the terms and conditions of the Creative Commons Attribution (CC-BY) license (https://creativecommons.org/licenses/by/4.0/). 
The propensity to be "overly positive" when forecasting and planning tasks is viewed as optimism bias [7]. Lovallo and Kahneman [8] discovered optimism bias within individuals to overestimate their ability to identify and manage risks. Similar forms of overconfidence have been reported in organisational dynamics [4], and locking-in-undelivered goals [9], subsequently affecting practices such as handling of information, management, and effective communication [10]. Ultimately, without recognising and accounting for optimism bias risk, decisions made are based on project actors' heuristics [11]. These decisions can negatively impact time and costs, limiting the overall productivity and performance of a project.

Research on cost overruns progresses along two distinct schools of thought (SOT). The deterministic or empirical school [12-15] evolved from investigating the planning and managing of projects that focus on a rational outcome for cost overruns through performance metrics use and their shortfalls. This empirical school established rationalistic logicbased planning, formal processes, and analytical techniques for forecasting future outcomes, but with the constraint of avoiding uncertainty in order to achieve certainty despite engaging the subjective human element. As a result, the behavioural school of thought in cost overrun research developed [7, 16-18] along with the assumption that the root cause of cost overruns is delusion, which is based on the project actors' individual biases and strategic misrepresentation (the deliberate intent to deceive in order to gain project acceptance). While it is acknowledged that cost overruns are a widespread issue and have garnered considerable interest from stakeholders, the proposed solutions are limited without understanding where this tendency is most pronounced in projects. Although scholarly works on delays and cost overruns abound, it is unclear at the moment how cost overrun is defined, why it occurs, or how to best circumvent it [19]. This gap warrants the need to investigate the psychological effects/tendencies of decision-makers influence on projects. Additionally, there are few attempts to quantify the degree of optimism bias among project planners and decision-makers in the construction sector, and there are no studies documenting small island Caribbean. Until now, little research has been conducted on the psychological factors influencing project actors' optimal decision-making abilities in construction, necessitating and justifying the need for further research.

This research aims to quantify the level of optimism bias inherent to project participants in Trinidad and Tobago's construction industry through the theoretical lens of uncertainty and indeterminateness. To achieve this, the study will investigate the relationship between optimism bias and time and cost overruns in construction management processes. The research focused on three objectives, namely, to determine the level of bias among project participants, to rank time and cost overrun causes according to the participants' bias score and to establish a mitigation strategy using "contingency time windows" built into a schedule where delays beyond the control of the project team are expected to occur in public sector projects. As a result, this research introduces a method by which optimism bias can be measured and accounted for in the construction sector.

\section{2- Literature Review}

A delay event, traditionally described as an event yielding an overrun in allocated time beyond a planned completion date contracting parties agreed for project delivery [20], can result in cost overruns [21]. Although there is no one universal definition for cost overruns [22], this research aligns with the interpretation by Ahiaga-Dagbui, et al. [12] as "the difference between project completion cost and budgeted cost at project approval". Cost overruns are influenced by variables within the political, social, technical, and psychological root causes [19]. Political root causes are exemplified where planners and promoters of projects intentionally overestimate benefits and underestimate the cost of increasing the viability of a project's acceptance and approval [23, 24]. This strategic misrepresentation [25] leads to inferior projects accepted with higher risks of contracted time and budget overruns, with failed promised benefits. These dishonest practices emanate directly from organisational pressure along with political interference [24], with the intentional mind-set to deceive [26] tantamount to fraudulent misrepresentation such as bid-rigging and collusion [27, 28]. Other main political factors such as hostile political conditions, weak project organisational structures[29], lack of consensus, bureaucracy and interagency conflict, contractual relationships, and manipulation of information [1, 30-33] contribute to time and cost overruns.

Technical root causes such as errors in project design, omissions in project documentation and procurement selection $[34,35]$ manifest as variations in projects, typically encountered as errors or bill of quantities under measurement, and changes in design [36]. Hickson and Ellis [37] stated that such technical factors affect the productivity of projects within Trinidad and Tobago. Similarly, technical factors which were found to be major contributors to delays and cost overruns prior to the commencement of construction activities are clarity of technical specifications and poor tendering documents [39], poor planning among stakeholders [40], and client's decision making processes [15]. During construction, change orders [14], construction methods [38], quality of equipment and machinery supply [41] and the lack of specialised workers and competency [42]. Social root causes emanate from the influence of society [43] which contribute to project delays and cost overruns. Additional social factors include community and local involvement, labour strikes [43], protest against excessive noise from work, environmental restrictions and impact [33] and historic preservation [44]. 
More recently, project studies have linked psychological influences, particularly optimism bias, as a dominant root cause contributing to cost and schedule overruns [45]. Psychological factors, or factors related to both the mental and emotional state of an individual [46], can lead to biases in judgement, such as ambiguity effects, anchoring, planning fallacy, and optimism, which negatively influence human judgements [47]. Optimism Bias is recognised in decision making on projects through the predisposition for "overly positive" predictions in forecasting or planning outcomes [7]. Thus success measures and benefits are overestimated unintentionally, as opposed to strategic misrepresentation. Time overruns on projects based on optimism bias result from a phenomenon known as the planning fallacy [48]. Regardless of the actual performance of previous similar projects, the tendency of the project planner to ignore distributional information, knowledge and experiences, and underestimate one's tasks and schedules, is the manifestation of optimism bias when similar tasks and schedules are actually longer in duration. The planning fallacy also states that individuals display a level of pessimism bias when predicting or observing others' tasks and plans, generally overestimating the actual duration. To overcome such cognitive bias, project decision-makers rely on heuristics or mental shortcuts to make judgements and decisions [49]. There are pros and cons to the use of heuristics in projects. Limitations of resources and information, and uncertainty and/or complexity of the problem require astute problem-solving skills and quick decision making [50] as time is often a constraint, but even informed practitioners are prone to severe mistakes in judgement [11]. Overreliance on these mental shortcuts can, without informed awareness, can circumvent critical analysis and hinder decision making [51]. A detailed listing of 81 causal factors contributing to both delays and cost overruns were extracted from the literature review. These factors were categorised into the leading root causes as shown in Table 1.

Table 1. Compiled list of factors contributing to delays and cost overruns.

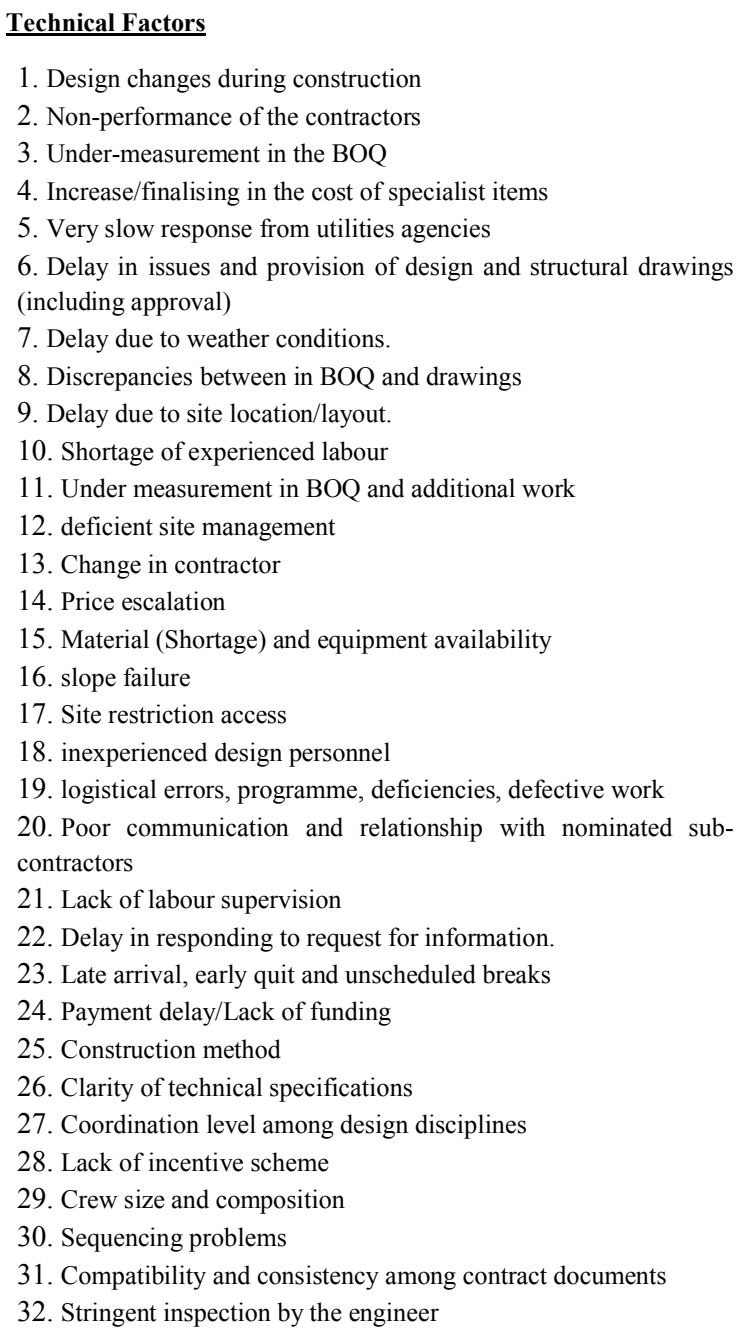

1. Design changes during construction

2. Non-performance of the contractors

3. Under-measurement in the BOQ

4. Increase/finalising in the cost of specialist items

5. Very slow response from utilities agencies

6. Delay in issues and provision of design and structural drawings (including approval)

7. Delay due to weather conditions.

8. Discrepancies between in BOQ and drawings

9. Delay due to site location/layout.

10. Shortage of experienced labour

11. Under measurement in BOQ and additional work

12. deficient site management

13. Change in contractor

14. Price escalation

15. Material (Shortage) and equipment availability

16. slope failure

17. Site restriction access

18. inexperienced design personnel

19. logistical errors, programme, deficiencies, defective work

20. Poor communication and relationship with nominated subcontractors

21. Lack of labour supervision

22. Delay in responding to request for information.

23. Late arrival, early quit and unscheduled breaks

24. Payment delay/Lack of funding

25. Construction method

26. Clarity of technical specifications

27. Coordination level among design disciplines

28. Lack of incentive scheme

29. Crew size and composition

30. Sequencing problems

31. Compatibility and consistency among contract documents

32. Stringent inspection by the engineer

\section{$\underline{\text { Political Factors }}$}

43. Owner's representative intervention with site management and operatives

44. Hostile political conditions

45. Delay in approval of completed work by client

46. Obtaining permission from local authorities

47. A poor organisational structure for client or consultant

48. Changes in government regulations and laws

49. Poor means of contracting.

50. Conflict between owners and other parties

51. Poor coordination among parties

52. Improper planning during the bidding stage

53 . Low priority by the state

54. Poor consultant work

55. local controversy

56. Regulations (lawsuits)

57. Stakeholder and local opposition

58. Lack of consensus (Insufficient political support)

59. finding an effective public sector champion

60. Laws and regulations empowering community groups

61. bureaucracy and interagency conflict

62. Government's tendency to maximize its budget and hide the true cost. 63. Manipulation of information

64. Contractual relationship (Contract modification/ Negotiation of obtaining contract, poor contract management etc.)

\section{Psychological Factors}

65. Unrealistic scheduling and expectation of labour

66. Motivation for labour

67. Lack of periodical meetings with crew leaders

68. Unrealistic inspection and testing methods proposed in contract

69. Consultant or architect's reluctance for change

70. High level of uncertainty

71. Raising false expectations

72. short-term thinking and tactical delays 


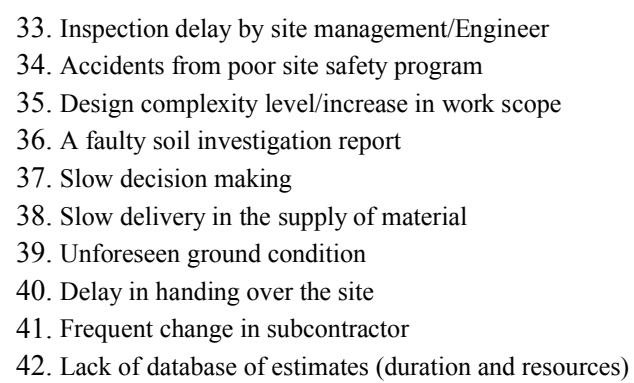

\author{
$\underline{\text { Social Factors }}$ \\ 73. Disruption to the contractor's schedule because of the close proximity \\ of existing schools \\ 74. Interruption by locals demanding employment. \\ 75. Protest against excessive noise from work \\ 76. Environmental restrictions (excessive noise) \\ 77. Theft and vandalism of materials \\ 78. Labour interference and congestion \\ 79. historic preservation consultation \\ 80. Environmental impacts (fish/wildlife/endangered species issues, \\ wetlands) \\ 81. Labour disputes and strikes
}

In developed nations such as the United Kingdom, HM Treasury [9] recognised the inherent nature of optimism bias by professionals in estimating key project parameters such as capital and operating costs, duration and the intended delivery of benefits by the project. Public sector professionals are now mandated to account for optimism bias, documented in the revision to "The Green Book" [9]. Mitigation strategies such as Reference Class Forecasting and due diligence processes [45] are proposed as countermeasures to curb optimism bias during project planning. However, Son and Rojas [4] and Shelbourn et al. [10] observed the continued prevalence of optimism bias within organisational dynamics; its impact on stakeholders, communication, and information handling depends on the size and complexity of projects. Moreover, modern construction techniques and procedures are void of failsafe measures such as "plan reliability" [52] to prevent optimism bias influencing the critical path and productivity during project planning and construction management.

According to the literature, there are sufficient studies accounting for optimism bias and its impact, but few quantify this phenomenon or ascribe a degree of importance to specific factors. Consequently, the central question explored is whether optimism bias is overlooked in construction management by planners and decision-makers? To address this knowledge gap, this research uses two sub-questions to examine the prevalence of optimism bias among public sector project professionals in Trinidad and Tobago, a Caribbean SIDS.

R.Q.1 What are the main delay and cost overrun factors project decision-makers tend to exert bias based on optimism?

R.Q.2 How can a bias score be assigned to project decision-makers to determine optimism or pessimism?

\section{3- Research Methodology}

The research method followed a three-stage process. The literature review stage allowed for the compilation of a comprehensive list of 81 delay factors in building construction projects linked to optimism bias. The second stage was a pilot survey involving three experts in the project management and construction management fields with knowledge of optimism bias in the construction sector. This pilot survey engaged the experts in an open discussion on the influence of optimism in the Caribbean and the relevant delay factors typically influenced by optimism bias. These semi-structured interviews resulted in a list of 24 delay factors that could be relatable within the SIDS's construction context. [36, 37].

The final stage involved the development of a questionnaire survey consisting of three sections. The first section requested demographic inputs, namely gender, years of experience, age and job position. Section two contains the 24 delay factors group under the main headings of political, technical, social, and psychological root causes. To determine an optimism bias score, the direct method approach was adopted, modelled along Heine and Lehman [53], and Breakwell et al. [54] methods. Theoretically, the direct approach method yields a strong optimism bias effect compared to the indirect method approach. The direct approach utilized an 11-point Likert scale, with numbers ranging from -5 to 5 , as it increased the probability of establishing optimism bias among individuals [54]. Participants were asked to rate the likelihood of the delay events, both negative and positive occurring. Based on the scores assigned, a "bias score" was obtained. "-5" is very much lower than the average project manager's probability, " 0 " represents both equal probabilities, and " 5 " represent a very much higher than the average project manager's probability. Section three consisted of eight questions, two of which were open-ended, with the aim of gathering details in identifying optimism bias and possible mitigation strategies. A hundred and five questionnaires were administered to the targeted public sector project participants. In total, 53 responses were received with a 52\% return rate, which exceeded the Moser and Kalton [55] minimum return rate of less than $40 \%$, which is considered bias and of insufficient importance. Figure 1 provides a flowchart of the research approach undertaken for this study. 


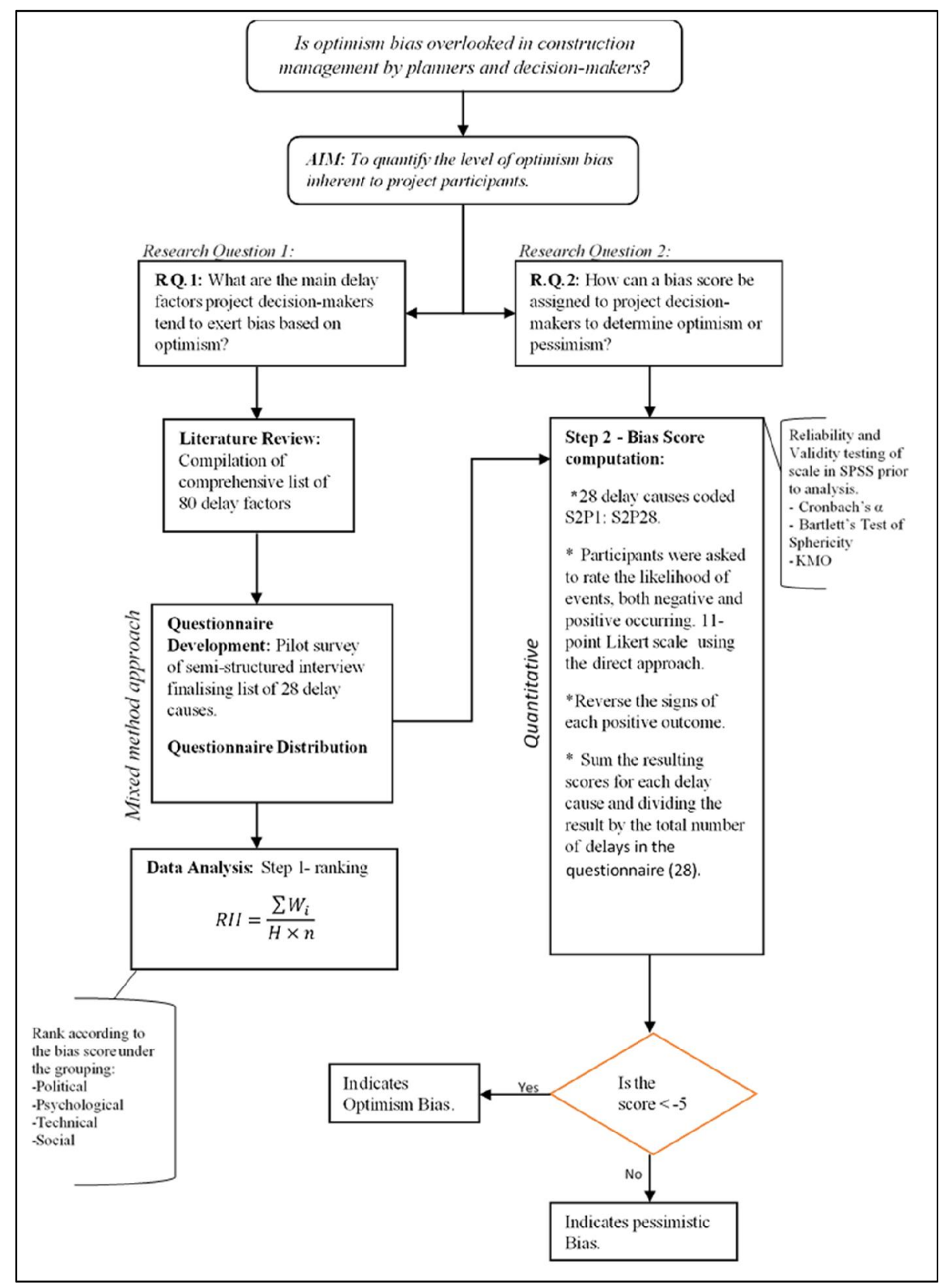

Figure 1. Flowchart of research activities.

\section{3-1-Reliability and Validity}

The reliability of the scale used to measure optimism bias among participants in the construction industry was determined using Cronbach's $\alpha$ index. The value of $\alpha$ is contingent on the number of variables within the questionnaire and the correlations between them. An $\alpha$ of 0.8 and greater is considered reliable [56, 57]. Statistical Package for Social Science (SPSS $®)$ software was used to analyse the survey results. An $\alpha$ value of 0.895 (89.5\% scale reliability) was obtained, confirming the reliability and internal consistency of the scales. The Bartlett's Test of Sphericity (examines the interdependency of the subscales) was 0.000 , less than the cut-off point of 0.05 , confirming the validity of the construct [57]. Finally, the Kaiser-Mayer Olkin Measure of Sampling Adequacy (KMO) test examines the scale sufficiency. The KMO value for the sample was 0.744, which was above the cut-off value of 0.5 [56].

\section{3-2-Measuring Optimism Bias}

For the purpose of simplification in the calculation of the bias score and data analysis in SPSS, the 28 delay causes were coded. S2P1: S2P28 codes (where S2 implies Section 2 and P1, the Probability of delay cause 1). S2P25- S2P28 represented positive events as opposed to delay causes; as such, the signs of the scores were reversed, i.e. -3 becomes +3 . The participants' bias score was obtained by summing the resulting scores for each delay cause and dividing the 
result by the total number of delays in the questionnaire (28). A score $<0$ indicates the presence of optimism bias, a score $=0$ indicates no bias, and scores $>0$ indicates pessimistic bias" [54]. The average respondents' bias score, the average root cause bias score and the average bias score of the positive outcomes were subsequently calculated.

\section{3-3-Demographics- Test of Statistical Significance (ANOVA and t-test)}

An Analysis of Variance (ANOVA) was performed to compare differences in optimism bias of sample means based on the demographics collected to determine whether the result is statistically significant at a $5 \%$ and $10 \%$ confidence interval $(\mathrm{p}<0.05$ and $\mathrm{p}<0.1)[56,58]$. Assuming a null hypothesis that the population means are equal (no optimism bias), a one-way ANOVA test was carried out on the following independent variables: Age Group, job position, years' experience; the dependent variable, in this case, was the respondent bias score (Optimism Bias, No Bias, Pessimistic). If there is a significant difference between the test sample, then the Least Significant Difference (LSD) Post Hoc test or Tamhane's T2 Post Hoc for heterogenous was conducted to illustrate the variables that showed a significant difference between them.

\section{3-4-Relative Important Index (RII)}

The Relative Important Index (RII) is a popular and effective ranking technique used in construction research [59, 60]. The RII values in this research assigned the first rank to the lowest value because delay causes indicate the strongest presence of optimism bias at the lowest RII score. Hence, the lower value of RII indicated an optimistic response towards the incident variable. The equation is as follows:

$R I I=\frac{\sum W_{i}}{H \times n}$

Where: $W_{i}=$ the weight assigned to the $i^{\text {th }}$ option, which ranges from -5 to 5 within the Likert scale; $H=$ the highest ranking available (i.e. 5 in this case); $n=$ the total number of participants.

\section{4- Results and Discussion}

From the survey sample, $51 \%$ of the responses came from independent consultants (Engineers, project managers and quantity surveyors), $40 \%$ were engineers and project managers representing the client (public sector managers/ engineers), and $10 \%$ were private-sector contractors and construction academics. Table 2 shows the overall average bias scores obtained for each stakeholder. From the sampled population, participants displayed pessimism in their responses, with independent consultants experiencing the highest average bias score of 1.96 and public sector representatives of 1.71. This means that participants acknowledge that there is a relatively high likelihood of delay occurrences in public sector projects they are involved in compared to similar private sector projects executed by their peers. Based on the pessimism bias expressed, it is inferred that participants are, in fact, aware of the causes of project delays and cost overrun and its occurrence under their management.

Table 2. Average bias scores based on participants' position.

\begin{tabular}{lccc}
\hline Participants current position & Number of participants & Overall average bias score & Positive outcome bias score \\
\hline Consultants & 27 & 1.96 & 0.78 \\
Contractor & 3 & 1.63 & -2.25 \\
Client & 21 & 1.71 & -0.92 \\
Academics & 2 & 1.23 & 1.50 \\
\hline
\end{tabular}

Participants were subsequently provided questions with positive outcomes, i.e. the probability of successfully completing a project within the planned schedule and budgeted costs and the probability of being awarded a contract without intentionally overestimating benefits and underestimating time and costs. It is observed that consultants and academics were consistent in their perception, maintaining a pessimistic bias score. However, both contractor and client groupings demonstrated the presence of optimism bias, with contractor's representatives being more optimistic of achieving project success in terms of time and cost (-2.25) as compared to client's representatives (-0.92). These findings compare favourably to a similar relationship put forward by Fischhoff, et al. [61], where individuals tend to be overly optimistic about the outcome of their own plan, justifying the planning fallacy concept.

A similar pattern of pessimism was revealed for delay and cost overrun root cause groupings. The sample surveyed expressed a relatively high pessimistic bias score for technical root causes, followed by psychological, political and social, respectively, in that order. However, a neutral position was observed for the lack of either optimism or pessimism bias when presented with positive outcomes within the root cause groupings, as shown in Table 3 . 
Table 3. Average bias score base on the delay factor grouping.

\begin{tabular}{cc}
\hline Delay factor root cause groups & Average bias score \\
\hline Political & 2.17 \\
Technical & 2.54 \\
Social & 0.87 \\
Psychological & 2.20 \\
Positive Outcome & -0.04 \\
\hline
\end{tabular}

The Relative Importance Index (RII) values for each delay cause was calculated to ranked delay factors according to their bias scores. Table 4 summarises the ranking of each delay cause overall and within their root cause grouping. Based on the rank of the RII, participants tend to exert higher levels of optimism bias to social issues, followed by technical, political and finally psychological. Therefore, psychological root causes tend to possess the least relative importance among the sample project participants. Interestingly, the top four ranked factors were social delay causes. From the results, we can infer that project actors are highly sensitive to social and environmental issues and their influence on a project. In term, an extra cautious approach will be adopted in any risk mitigation strategy. For example, to prevent labour disputes and strikes, the project team will accept team members who may not have the necessary skill set for the particular position. A project manager will be optimistic that the learning curve of the new team member can be easily and quickly bridged, while the local content addition may not want to deliberately delay the learning process in an effort to lengthen the project and consequent longer employment status. Similarly, participants tend to express a higher level of optimism to social issues as compared to other root cause groupings, with "schedule disruption due to location" ranking first overall.

Within the technical grouping, the top-ranked factors were "resource shortage" and "inclement weather", while the last ranked factor is "payment delays/funding". Participants therefore perceived projects are least likely to be influenced by shortages in material, equipment and labour, and seasonal weather patterns. On the other hand, delays and cost overruns are more likely to be experienced by payment and funding issues. Similarly, under political root cause, participants view "political interference" as least likely to influence projects compared to improper planning during the bidding stage. For psychological root cause, "short-term thinking and heuristics" had the highest optimism bias rank.

Based on the findings, the optimistic responses of the participants were directly linked to several reasons given within the Commission of Enquiry [62] into construction projects in Trinidad and Tobago. To this date, the planning of public sector projects failed to identify delusion, deception and lack of funding as contributing factors to project delays. Plotch [33] observed a similar trait in absconding from responsibility when a report is submitted from one governing political party to another. However, a pessimistic score on payment delays and improper planning as a major contributing factor to delays in public sector projects $[33,37]$ suggests that decision-makers are aware of these issues.

Table 4. Ranking of factors based on the bias score inhibiting effective project time and cost delay.

\begin{tabular}{|c|c|c|c|}
\hline 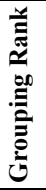 & 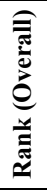 & Delay Cause & RII \\
\hline & & \multicolumn{2}{|l|}{ Social } \\
\hline 1 & 1 & Schedule disruption due to location & 0.101 \\
\hline 2 & 2 & Environmental impacts and historic preservation & 0.132 \\
\hline 3 & 3 & Labour disputes, strikes, and protest & 0.2 \\
\hline \multirow[t]{2}{*}{4} & 4 & Accidents, theft and vandalism & 0.264 \\
\hline & & \multicolumn{2}{|l|}{ Technical } \\
\hline 1 & 5 & Resource shortage & 0.347 \\
\hline 1 & 5 & Inclement weather & 0.347 \\
\hline 3 & 11 & Poor communication & 0.393 \\
\hline 4 & 12 & deficient site management/ supervision & 0.415 \\
\hline 5 & 14 & Under-measurement in the BOQ & 0.426 \\
\hline 6 & 18 & Delay in issuing design and drawings & 0.513 \\
\hline 7 & 19 & Design errors/ Omissions & 0.517 \\
\hline 8 & 20 & Design changes during construction & 0.615 \\
\hline 8 & 20 & Non-performance of the contractors & 0.615 \\
\hline 10 & 23 & Very slow response from utility agencies & 0.683 \\
\hline 11 & 24 & Payment delay/Lack of funding/ incentive scheme & 0.717 \\
\hline
\end{tabular}




\begin{tabular}{lllc}
\hline & Political & \\
\hline 1 & 7 & Political interference & 0.353 \\
2 & 8 & Low priority of project & 0.37 \\
3 & 9 & Manipulation of information \& Bid rigging & 0.385 \\
4 & 10 & Hostile political conditions & 0.389 \\
5 & 16 & Contract modification/ Negotiation after contract award & 0.468 \\
6 & 22 & Improper planning during the bidding stage & 0.638 \\
\hline & & Psychological & 0.419 \\
\hline 2 & 13 & Short-term thinking and Heuristics & 0.430 \\
3 & 15 & High level of uncertainty and raising false expectations & 0.472 \\
\hline
\end{tabular}

The results of the ANOVA test in Table 5 showed that all independent variables (age, position and experience) produced non-significant statistical results at a 5\% significance level. This indicates that age group, position, and experience do not provide compelling statistical evidence of the optimism bias effect on the population. However, the independent variable "age group" $(0.05<\mathrm{p} \leq 0.099<0.1)$ and position $(0.05<\mathrm{p} \leq 0.066<0.1)$ implies marginal significance at a $10 \%$ significance $[56,58]$, suggesting there is weak evidence of optimism bias in the population. An independent samples t-Test was further conducted to determine if there was any significant difference between males and females on the Bias Scores obtained. From the results obtained, the 36 males had a mean bias score of -0.4028 , and the 17 females had a mean bias score of 0.7353 for the positive bias outcome. However, the results were not statistically significant at the $95 \%$ confidence level $(p \leq 0.163)$ [58]. Thus, there is little evidence of the effect optimism bias varies by gender in the population. Levene's test for equality of variances further confirmed that the variance for males and females do not differ significantly from each other $(p \leq 0.267$ and 0.428$)$ as it relates to the bias score of the participants. A main limitations in the analysis was the relatively small sample size of 53 participants, which can affect the statistical significance of the results. However, since optimism bias is a relatively new concept to construction professionals in the Caribbean, deeper insights from the participants' knowledge on this phenomenon were warranted. This was gathered by analysing responses given from open ended questions.

Table 5. ANOVA comparison for the independent variables: "Age Group", "Position", and "Field Experience".

\begin{tabular}{cccccc}
\hline & \multicolumn{7}{c}{ ANOVA (between groups) } \\
\hline & Sum of squares & df & Mean Square & F & Sig. \\
\hline Age Group (Bias) & 8.717 & 3 & 2.906 & 2.207 & $\mathbf{0 . 0 9 9}$ \\
Age Group (PBias) & 64.528 & 3 & 1.317 & 2.060 & 0.118 \\
Position (Bias) & 1.594 & 3 & 0.531 & 0.363 & 0.078 \\
Position (PBias) & 53.591 & 3 & 17.864 & 2.559 & $\mathbf{0 . 0 6 6}$ \\
Experience (Bias) & 6.807 & 3 & 2.269 & 1.674 & 0.185 \\
Experience (PBias) & 51.043 & 3 & 17.014 & 2.419 & $\mathbf{0 . 0 7 7}$ \\
\hline * Bias $=$ Overall Optimism Bias of the group. PBias= Positive Optimism Bias of the group & &
\end{tabular}

* Bias = Overall Optimism Bias of the group, PBias= Positive Optimism Bias of the group

Section 3 of the questionnaire included four opened-ended questions to explore context-specific issues of the influence of optimism bias on delays and cost overruns, and more specifically, the participants' understanding of optimism bias. The first question was generic in nature, requesting participants to state their perception of the leading cause of cost overrun and recommendations to curtail this problem. Financial concerns, such as budgeted funding for the project, cash flows and payments, were of major concern. However, several descriptions had overlapping issues. Poor planning and strategy overlapped with strategic misrepresentation and financial concerns.

The second question was specific, asking participants whether they heard of the term optimism bias. Not surprisingly, $62 \%$ of the respondents have never heard of the term optimism bias. This lack of knowledge of optimism bias would have the propensity to skew the results obtained. Literature of optimism bias in construction is also non-existent in the Caribbean context and not taught in construction programmes. However, when provided with a definition as the "inclination for people to be overly positive when making predictions about the outcome of the future planned action"[7], and asking whether optimism bias exists in the planning stage of a construction project, 96\% agreed optimism bias is indeed present among themselves as planners and decision-makers on public sector projects. Thus, by reframing the question and providing a definition of optimism bias, participants' perceptions changed from negative (not knowing) to positive (high acceptance). This cognitive shift in perception underlies probing the effect of optimism bias. 
Thus, the subsequent question probed into optimism bias effects, such as whether participants believe benefits are overestimated while project cost is underestimated. $85 \%$ of the participants agreed that benefits are overestimated and cost underestimated. Several rationales were provided, such as benefits stated on projects are not realistic but required, even necessary, to show social development and gain political support. Also, public sector acceptance is driven by the lowest costs; thus, project managers deliberately underestimate costs. Contractors deliberately underbid to ensure a project is given life and proceed with this optimism due to the lack of formal risk assessment scenarios. Several responses also suggested that ministries and state agencies are not concerned with the worst-case scenario; unforeseen items of work and detailed scope are left after contract award.

The final question explored the issue of managerial failure to identify delay concerns during planning that could negatively impact productivity on construction projects. $94 \%$ of the respondents agreed that these delay causes are not identified by project managers, which leads to reoccurrence on other similar projects. Managers' dominant reason for these failed opportunistic behaviours is to improve their agency through favouritism in the award of contracts. Respondents agree that politics influence public sector construction contracts through distortion of scope, deliberate cost, and schedule manipulation, ultimately resulting in sizable cost overruns. A senior public sector manager stated:

"We need to distinguish between cost escalation (anticipated growth in a budgeted cost due to factors such as inflation) and cost overrun. I am inclined to believe that anything relating to cost estimates, bills of quantities, budgets etc., ought to be prepared by a Chartered Quantity Surveyor. In other words, being able to estimate the cost of an item/s remains key/critical to delivering a solid project plan. Hence, without extensive estimation skills, quantity surveyors usually find it somewhat difficult to provide accurate estimates.",

Opposing views were also shared by $13 \%$ of the respondents, citing reputational impacts, as a contractor's project manager suggested:

"A seasoned contractor seldom makes errors with cost. As Project Manager, I have my pride and a reputation to maintain."

These findings are aligned to those in developed nations [24] and the Caribbean SIDS [28, 29], affirming that misinformation of a project's cost, risk and benefits are more of a norm than an exception. The causal chain starts with misinformation by political influences. However, the project team is left to make the best of a subpar project. Their optimism to ensure project success masks the reality of the outcomes. While the technical team attempts to deliver such projects under constrained conditions and lacks awareness of the initial misinformation, it imposes unanticipated consequences. Scenarios are involuntarily generated to ensure the successful outcome of projects, while failure is ignored. Typical contingencies within the project's contract are unable to be an effective control in mitigating these risks.

Such over-optimism relates to delusions or honest mistakes and deliberate strategic deception, resulting in delays, cost overruns and benefit shortfalls [24]. Although both delusion and deception co-exist in projects [25], the strong presence of delusion or optimism bias can be accompanied by a weak presence of deception, such as strategic misrepresentation. Delusional optimism explains the performance of construction projects that appears to absolve the planner's responsibility [25]. Yet, when forecasters were asked about the possible causes of inaccurate information, they fail to mention the possibility of optimism as a causal factor [63]. The obvious explanation for this is that optimism bias is an unconscious form of delusion and therefore not explicitly reflected upon by individual forecasters [24]. Optimism bias is a powerful explanation of cost overrun and projects delays, and naïve planners and decision-makers, $62 \%$ of our sample, are systemically prone to repeat similar errors and oversights without learning from past experiences [24]. Unfortunately, the overwhelming weight of evidence in the literature revealed that experience planners and decisionmakers also fall prey to optimism bias.

\section{4-1-Proposed Mitigation Strategy to Curb Optimism Bias in Trinidad and Tobago Construction Sector}

Optimism bias is officially recognised as a risk in public sector projects in the United Kingdom through research and policy initiatives. Through the "The Green Book", implemented by HM Treasury in 2003, optimism bias, together with uncertainty and risk, are identified under section A5 [9]. A mitigation strategy to curb cost overruns due to optimism bias is reference class forecasting (RCF). A Similar recommendation is made for Caribbean SIDS. Currently, public sector project professionals are not fully aware of the impacts of optimism bias. Implementing a government policy of recognising optimism bias and subjecting projects to RCF truer cost estimates on projects can be realised. Originally conceptualised by Kahneman [64] to report for the cognitive tendency found in forecasting by individuals, RCF involves analysing distributional data of similar and statistically meaningful classes of projects and taking "an outside view" position of the project. Using relevant and statistically meaningful project data, a probability distribution of the selected reference class is developed, and the specific project under evaluation is compared to the reference class distribution to determine the likely outcome [63]. The main limitation of this method is that it fails to forecast the possible outcome of projects lying outside the historical guides available for reference. 
Also, the "Contingency Time Window" (CTW) concept is a new system to be introduced into tenders in a similar manner as RCF. It is defined as an agreed duration within the contractual period reserved for the project's use and its variables. Parties are not held liable for delays when the CTW period is enforced. Based on distributional data of delays, a CTW can be established for similar projects. For example, delays in public housing projects of similar size can be accounted for and placed in a reference class distribution. During tendering, the contractor will be requested to insert his planned schedule plus the CTW determined from the reference class. In the absence of distributional data, a reasonable time frame can be determined from a consensus or Delphi approach. The contingency window will further consider known-unknown risks, such as errors and omissions in the contract documents [65].

From the survey conducted, $68 \%$ of the participants were in support of the development of a "time contingency window", which can reduce inaccuracy and bias in the early planning stage. They believed that it could: 1 . Improve the overall confidence of the project in a probabilistic sense, and 2. Provide enough time to prepare a fully coordinated value engineered design. On the other hand, $32 \%$ of the participants believed that the time contingency window could encourage the parties involved in the project to be complacent. Regardless of such opposing views, the implementation of CTW can improve project control and accountability, directly reducing delays and, ultimately, cost overruns on public sector projects.

\section{5- Conclusions}

On public sector construction projects in the Caribbean, optimism bias is not recognised. The construction industry makes a scant effort to quantify the degree of optimism expressed by project planners and decision-makers. This research's primary contribution was the development of such strategies to close this gap. To measure the level of optimism bias among construction professionals, Breakwell et al. [54] method was adopted and modified within the context of the Caribbean SIDS construction industry by assigning bias scores to delay causes. Following that, delay causes were ranked using RII based on the participants' bias scores. The reliability and validity tests established the questionnaire's appropriateness use for this study.

When asked about the likelihood of the effect of optimism bias on delay causes occurring on a project, the ANOVA test revealed marginal statistical significance among the age groups. Similarly, the participants' position and field experience were marginally significant concerning their positive bias score (i.e. scores obtained from the probability of positive outcomes). The study also found that the results were constrained by the values chosen for the dependent list and the small sample size. It is critical to use the actual bias score obtained by the participants rather than a value-label system when selecting such data for analysis. From the results obtained, contractors and project managers revealed a higher degree of optimism bias as it relates to a project experiencing delays and cost overrun during its duration. This finding answers the research question that there is optimism in the execution of projects which is not accounted for by planners and decision-makers. The limitation here is that the bias score was influenced by the outcome provided. The positive outcomes provided to the participants produce a higher optimism bias. It is, therefore, recommended that an equal distribution of positive and negative outcomes be presented for future research. In capturing the amount of bias amongst project managers and decision-makers, negative outcomes of real-life scenarios which are experienced on the construction site can be used.

The main optimistic delay factors were identified as 1. Disruption to the contractor's schedule because of location 2 . Environmental impacts and historic preservation 3. Labour disputes, strikes, and protests, and 4. Accidents, theft and vandalism. However, the most pessimistic factors were. 1. Payment delays, 2 . Slow response from utility agencies, and 3. Improper planning during the bidding stage. The open responses by the participants further confirmed that a lack of funding and poor planning are major contributing factors to project delays. They further admitted a lack of awareness of optimism bias and the practice of strategically manipulating the true cost of a project by underestimating the budget in an attempt to gain project and contract approval. Therefore, such delusion and deception need to be addressed in all forms to ensure effective and efficient usage of taxpayer's monies. It is therefore proposed that a contingency "time window" be introduced within contractual documentation to reduce the reoccurring and resistant nature of these delays due to optimism bias and ensure reasonable and realistic expectations are established. Further research into contingency time windows is recommended.

\section{6- Declarations}

\section{6-1-Author Contributions}

Conceptualization, A.C. and S.H.; methodology, A.C., S.H. and H.M.; software, S.H.; validation, A.C., S.H. and H.M.; formal analysis, S.H.; investigation, A.C.; resources, A.C.; data curation, S.H.; writing-original draft preparation, S.H.; writing - review and editing, A.C. and H.M.; visualization, A.C.; supervision, A.C., and H.M.; project administration, A.C.; funding acquisition, A.C. All authors have read and agreed to the published version of the manuscript. 


\section{6-2-Data Availability Statement}

The data presented in this study are available in article.

\section{6-3-Funding}

The authors received no financial support for the research, authorship, and/or publication of this article.

\section{6-4-Acknowledgements}

The authors are thankful for the construction practitioners who provided comprehensive and important information necessary for this research.

\section{6-5-Conflicts of Interest}

The authors declare that there is no conflict of interests regarding the publication of this manuscript. In addition, the ethical issues, including plagiarism, informed consent, misconduct, data fabrication and/or falsification, double publication and/or submission, and redundancies have been completely observed by the authors.

\section{7- References}

[1] Aibinu, Ajibade Ayodeji, and Henry Agboola Odeyinka. "Construction Delays and Their Causative Factors in Nigeria." Journal of Construction Engineering and Management 132, no. 7 (July 2006): 667-677. doi:10.1061/(asce)0733-9364(2006)132:7(667).

[2] Simtette, J. "Accounting for Megaproject Dollars." Public roads 68, no. 1 (2004): 40-47.

[3] Taxpayers Alliance. "Beyond the Dome: Government Projects $£ 23$ Billion Over Budget." Available online: https://d3n8a8pro7vhmx.cloudfront.net/taxpayersalliance/pages/2038/attachments/original/1438685061/Beyond_the_Dome.pdf ?1438685061(accessed on July 2019).

[4] Son, JeongWook, and Eddy M. Rojas. "Impact of Optimism Bias Regarding Organizational Dynamics on Project Planning and Control." Journal of Construction Engineering and Management 137, no. 2 (February 2011): 147-157. doi:10.1061/(asce)co.1943-7862.0000260.

[5] Flyvbjerg, Bent, Nils Bruzelius, and Werner Rothengatter. Megaprojects and risk: An anatomy of ambition. Cambridge University Press, 2003.

[6] Al-Khalil, Mohammed I., and Mohammed A. Al-Ghafly. "Important Causes of Delay in Public Utility Projects in Saudi Arabia." Construction Management and Economics 17, no. 5 (September 1999): 647-655. doi:10.1080/014461999371259.

[7] Siemiatycki, Matti. "Managing Optimism Biases in the Delivery of Large-Infrastructure Projects: A Corporate Performance Benchmarking Approach.” 2008 First International Conference on Infrastructure Systems and Services: Building Networks for a Brighter Future (INFRA) (2008). doi:10.1109/infra.2008.5439642.

[8] Lovallo, Dan, and Daniel Kahneman. "Delusions of Success: How Optimism Undersmines Executives' Decisions." Harvard Business Review 81, no. 7 (2003): 1-10.

[9] Treasury, H. M. S. "The Green Book-Appraisal and Evaluation in Central Government 2003 TSO." (2003).

[10] Shelbourn, M., N.M. Bouchlaghem, C. Anumba, and P. Carrillo. "Planning and Implementation of Effective Collaboration in Construction Projects.” Construction Innovation 7, no. 4 (October 16, 2007): 357-377. doi:10.1108/14714170710780101.

[11] Emmons, Debra, Thomas Mazzuchi, Shahram Sarkani, and Curtis Larsen. "Mitigating Cognitive Biases in Risk Identification: Practitioner Checklist for the Aerospace Sector.” Defense Acquisition Research Journal 25, no. 1 (January 2, 2018): 52-93. doi:10.22594/dau.16-770.25.01.

[12] Ahiaga-Dagbui, Dominic, Simon D. Smith, Peter ED Love, and Fran Ackermann. "Spotlight on construction cost overrun research: superficial, replicative and stagnated." (2015).

[13] Love, Peter E.D., Dominic D. Ahiaga-Dagbui, and Zahir Irani. "Cost Overruns in Transportation Infrastructure Projects: Sowing the Seeds for a Probabilistic Theory of Causation.” Transportation Research Part A: Policy and Practice 92 (October 2016): 184194. doi:10.1016/j.tra.2016.08.007.

[14] Asiedu, Richard Ohene, and Ebenezer Adaku. "Cost Overruns of Public Sector Construction Projects: a Developing Country Perspective.” International Journal of Managing Projects in Business 13, no. 1 (May 6, 2019): 66-84. doi:10.1108/ijmpb-092018-0177.

[15] Johnson, Reshma Mary, and Robin Itty Ipe Babu. "Time and Cost Overruns in the UAE Construction Industry: a Critical Analysis." International Journal of Construction Management 20, no. 5 (November 13, 2018): $402-411$. doi:10.1080/15623599.2018.1484864.

[16] Flyvbjerg, Bent. "Delusions of success: comment on Dan Lovallo and Daniel Kahneman." Harvard Business Review 81, no. 12 (2003): 121-122. 
[17] Flyvbjerg, Bent. "Five Misunderstandings about Case-Study Research.” Qualitative Inquiry 12, no. 2 (April 2006): 219-245. doi:10.1177/1077800405284363.

[18] Flyvbjerg, Bent, Atif Ansar, Alexander Budzier, Søren Buhl, Chantal Cantarelli, Massimo Garbuio, Carsten Glenting, et al. "Five Things You Should Know About Cost Overrun." Transportation Research Part A: Policy and Practice 118 (December 2018): 174-190. doi:10.1016/j.tra.2018.07.013.

[19] Chadee, Aaron Anil, Xsitaaz Twinkle Chadee, Indrajit Ray, Abrahams Mwasha, and Hector Hugh Martin. "When Parallel Schools of Thought Fail to Converge: The Case of Cost Overruns in Project Management." Buildings 11, no. 8 (July 27, 2021): 321. doi:10.3390/buildings11080321.

[20] Assaf, Sadi A., and Sadiq Al-Hejji. "Causes of Delay in Large Construction Projects." International Journal of Project Management 24, no. 4 (May 2006): 349-357. doi:10.1016/j.ijproman.2005.11.010.

[21] Oyewobi, Luqman Oyekunle, Richard Jimoh, Bashir Olanrewaju Ganiyu, and Abdullateef Adewale Shittu. "Analysis of Causes and Impact of Variation Order on Educational Building Projects." Journal of Facilities Management 14, no. 2 (May 3, 2016): 139-164. doi:10.1108/jfm-01-2015-0001.

[22] Invernizzi, Diletta Colette, Giorgio Locatelli, and Naomi J Brookes. "Cost Overruns - Helping to Define What They Really Mean." Proceedings of the Institution of Civil Engineers-Civil Engineering 171, no. 2 (May 2018): 85-90. doi:10.1680/jcien.17.00001

[23] Flyvbjerg, Bent. "Design by deception: The politics of megaproject approval." Harvard Design Magazine, Spring/Summer 22 (2005): 50-59.

[24] Flyvbjerg, Bent, and Eamonn Molloy. "Delusion, deception and corruption in major infrastructure projects: Causes, consequences and cures." The international handbook on the economics of corruption, Cheltenham, UK, Northampton (MA), USA, Edward Elgar 2 (2011): 81-107.

[25] Flyvbjerg, Bent, Massimo Garbuio, and Dan Lovallo. "Delusion and Deception in Large Infrastructure Projects: Two Models for Explaining and Preventing Executive Disaster." California Management Review 51, no. 2 (January 2009): 170-194. doi: $10.2307 / 41166485$.

[26] Flyvbjerg, Bent, Carsten Glenting, and Arne Rønnest. "Procedures for dealing with optimism bias in transport planning." London: The British Department for Transport, Guidance Document (2004).

[27] Dorée, A. G. "Collusion in the Dutch Construction Industry: An Industrial Organization Perspective." Building Research \& Information 32, no. 2 (March 2004): 146-156. doi:10.1080/0961321032000172382.

[28] Chadee, Aaron Anil, Xsitaaz Twinkle Chadee, Abrahams Mwasha, and Hector Hugh Martin. "Implications of 'Lock-in' on Public Sector Project Management in a Small Island Development State." Buildings 11, no. 5 (May 8, 2021 ): 198. doi:10.3390/buildings 11050198 .

[29] Chadee, Aaron, Indrajit Ray, and Xsitaaz Chadee. "Systemic Issues Influencing Technical Certainty in Social Housing Programmes in a Small Island Developing State.” Buildings 11, no. 2 (February 12, 2021): 65. doi:10.3390/buildings 11020065.

[30] Abd El-Razek, M. E., H. A. Bassioni, and A. M. Mobarak. "Causes of Delay in Building Construction Projects in Egypt.” Journal of Construction Engineering and Management 134, no. 11 (November 2008): 831-841. doi:10.1061/(asce)07339364(2008)134:11(831).

[31] Doloi, Hemanta, Anil Sawhney, K.C. Iyer, and Sameer Rentala. "Analysing Factors Affecting Delays in Indian Construction Projects.” International Journal of Project Management 30, no. 4 (May 2012): 479-489. doi:10.1016/j.ijproman.2011.10.004..

[32] Marzouk, Mohamed M., and Tarek I. El-Rasas. "Analyzing Delay Causes in Egyptian Construction Projects." Journal of Advanced Research 5, no. 1 (January 2014): 49-55. doi:10.1016/j.jare.2012.11.005.

[33] Plotch, Philip Mark. "What's Taking So Long? Identifying the Underlying Causes of Delays in Planning Transportation Megaprojects in the United States." Journal of Planning Literature 30, no. 3 (January 8, 2015): 282-295. doi: $10.1177 / 0885412214566116$.

[34] Love, P., P. Davis, David Baccarini, Geoff Wilson, and Robert Lopez. "Opening Pandora's Box: Revisiting Procurement Selection in the Public Sector." In The Third Scottish Conference for Postgraduate Researchers of the Built \& Natural Environment (PRoBE). 2007.

[35] Love, Peter ED, Peter Davis, David Baccarini, Geoff Wilson, and Robert Lopez. "Procurement selection in the public sector: a tale of two states." (2008).

[36] Uff, J., and D. Thornhill. "Report of the commission of enquiry into the construction sector Trinidad and Tobago." Government of Trinidad and Tobago, Port of Spain, Trinidad and Tobago: Ministry of Finance (2010). Available online: www.jcc.org.tt/uffreport.pdf (accessed on May 2021).

[37] Hickson, Brent G., and Leighton A. Ellis. "Factors affecting construction labour productivity in Trinidad and Tobago." The Journal of the Association of Professional engineers of Trinidad and Tobago 42, no. 1 (2014): 4-11. 
[38] Shah, Raj Kapur. "An Exploration of Causes for Delay and Cost Overruns In Construction Projects: Case Study of Australia, Malaysia \& Ghana." Journal of Advanced College of Engineering and Management 2 (November 29, 2016 ): 41. doi:10.3126/jacem.v2i0.16097.

[39] Ahiaga-Dagbui, Dominic D., and Simon D Smith. "Rethinking Construction Cost Overruns: Cognition, Learning and Estimation." Journal of Financial Management of Property and Construction 19, no. 1 (April 7, 2014): 38-54. doi:10.1108/jfmpc-06-2013-0027.

[40] Asiedu, Richard Ohene, and Ebenezer Adaku. "Cost Overruns of Public Sector Construction Projects: a Developing Country Perspective.” International Journal of Managing Projects in Business 13, no. 1 (May 6, 2019): 66-84. doi:10.1108/ijmpb-092018-0177.

[41] Bakri, Adnan, M.F.M. Alkbir, Nuha Awang, Fatihhi Januddi, M. A. Ismail, Ahmad Nur Aizat Ahmad, and Izatul Husna Zakaria. "Addressing the Issues of Maintenance Management in SMEs: Towards Sustainable and Lean Maintenance Approach." Emerging Science Journal 5, no. 3 (June 1, 2021): 367-379. doi:10.28991/esj-2021-01283.

[42] Derakhshanalavijeh, Roya, and Jose Manuel Cardoso Teixeira. "Cost Overrun in Construction Projects in Developing Countries, Gas-Oil Industry of Iran as a Case Study.” Journal of Civil Engineering and Management 23, no. 1 (July 13, 2016): 125-136. doi:10.3846/13923730.2014.992467.

[43] Kaliba, Chabota, Mundia Muya, and Kanyuka Mumba. "Cost Escalation and Schedule Delays in Road Construction Projects in Zambia.” International Journal of Project Management 27, no. 5 (July 2009): 522-531. doi:10.1016/j.ijproman.2008.07.003.

[44] Roy, Debopam, and Satyanarayana N. Kalidindi. "Critical Challenges in Management of Heritage Conservation Projects in India." Journal of Cultural Heritage Management and Sustainable Development 7, no. 3 (September 14, 2017): $290-307$. doi:10.1108/jchmsd-03-2017-0012.

[45] Flyvbjerg, Bent. "Curbing Optimism Bias and Strategic Misrepresentation in Planning: Reference Class Forecasting in Practice." European Planning Studies 16, no. 1 (December 17, 2007): 3-21. doi:10.1080/09654310701747936.

[46] Watts, Logan L., Kelsey Medeiros, Tristan McIntosh, and Tyler Mulhearn. "Decision biases in the context of ethics: Initial scale development and validation." Personality and Individual Differences 153. No. 109609 (January 15 2020). doi:10.1016/j.paid.2019.109609.

[47] Caputo, Andrea. "A Literature Review of Cognitive Biases in Negotiation Processes." International Journal of Conflict Management 24, no. 4 (September 30, 2013): 374-398. doi:10.1108/ijcma-08-2012-0064.

[48] Shaikh, Fazal Ali, Nasurullah Odhano, and Suaathi Kaliannan. "Performance and Management of Cost in the Construction Industry.” Civil Engineering Journal 6, no. 7 (July 1, 2020): 1368-1374. doi:10.28991/cej-2020-03091554..

[49] Tversky, A., and D. Kahneman. “Judgment Under Uncertainty: Heuristics and Biases.” Science 185, no. 4157 (September 27, 1974): 1124-1131. doi:10.1126/science.185.4157.1124.

[50] Sprinkle, Zachary Joseph. "Heuristics in Construction Project Management." PhD diss., Virginia Tech, 2019. Available online: https://vtechworks.lib.vt.edu/bitstream/handle/10919/87089/Sprinkle_ZJ_T_2019.pdf?sequence=1\&isAllowed=y (accessed on May 2021).

[51] van Buiten, M., \& Hartmann, A. "Public-private partnerships: cognitive biases in the field." In P. Carrillo, \& P. Chinowsky (Eds.), Proceedings of the engineering project organization (EPOC 2013): 9-11 July 2013, Winter Park, Colorado (Working Paper Proceedings; Vol. 2013). EPOS.

[52] Ballard, Herman Glenn. "The last planner system of production control." PhD diss., University of Birmingham, 2000.

[53] Heine, Steven J., and Darrin R. Lehman. "Cultural Variation in Unrealistic Optimism: Does the West Feel More Vulnerable Than the East?” Journal of Personality and Social Psychology 68, no. 4 (1995): 595-607. doi:10.1037/0022-3514.68.4.595.

[54] Breakwell G. M., Fife-Schaw C., and Barneett J., Doing social psychology research-Chapter 3: Measuring Optimistic Bias. John Wiley \& Sons, 2008.

[55] Moser, C.A., and G. Kalton. "Survey Methods in Social Investigation" (March 2, 2017). doi:10.4324/9781315241999.

[56] Field, Andy. Discovering statistics using SPSS. London: London: Sage Publications, 2009.

[57] Anastasiadou, Sofia D. "Reliability and validity testing of a new scale for measuring attitudes toward learning statistics with technology." Acta Didactica Napocensia 4, no. 1 (2011): 1-10.

[58] George, Darren. SPSS for windows step by step: A simple study guide and reference, 17.0 update, 10/e. Pearson Education India, 2011

[59] Rao, Prakash B., and Culas Joseph Camron. "Causes of delays in construction projects-A case study." International Journal of Current Research 6, no. 6 (2014): 7219-7222. 
[60] Olawale, Yakubu Adisa, and Ming Sun. "Cost and Time Control of Construction Projects: Inhibiting Factors and Mitigating Measures in Practice." Construction Management and Economics 28, no. 5 (May 2010): 509-526. doi:10.1080/01446191003674519.

[61] Fischhoff, Baruch, Paul Slovic, and Sarah Lichtenstein. "Knowing with Certainty: The Appropriateness of Extreme Confidence." Journal of Experimental Psychology: Human Perception and Performance 3, no. 4 (1977): 552-564. doi:10.1037/0096-1523.3.4.552.

[62] Staw, Barry M. "The Escalation of Commitment to a Course of Action.” The Academy of Management Review 6, no. 4 (October 1981): 577. doi:10.2307/257636.

[63] Flyvbjerg, Bent, Mette K. Skamris Holm, and Søren L. Buhl. "How (In) accurate Are Demand Forecasts in Public Works Projects?: The Case of Transportation.” Journal of the American Planning Association 71, no. 2 (June 30, 2005): 131-146. doi:10.1080/01944360508976688.

[64] Kahneman, Daniel. "New challenges to the rationality assumption." Journal of Institutional and Theoretical Economics (JITE)/Zeitschrift für die gesamte Staatswissenschaft (1994): 18-36.

[65] Love, Peter E. D., Chun-Pong Sing, Brad Carey, and Jeong Tai Kim. "Estimating Construction Contingency: Accommodating the Potential for Cost Overruns in Road Construction Projects." Journal of Infrastructure Systems 21, no. 2 (June 2015): 04014035. doi:10.1061/(asce)is.1943-555x.0000221. 